* Mestranda em Direito Negocial pela Universidade Estadual de Londrina - UEL. Especialista em Direito Tributário pelo Instituto Brasileiro de Estudos Tributários (IBE) T. Especialista em Direito Constitucional pela Pontifícia Universidade Católica do Paraná - PUC. Graduada em Direito pela Universidade Filadélfia - UNIFIL. Pesquisadora. Advogada. Professora. E-mail: thayscanezin@gmail. com

** Doutoranda do Programa de Pós-Graduação em Estudos da Linguagem da UEL - PPGEL - UEL, sob a orientação da Profa. Dra. Edina Regina Pugas Panichi. Mestre em Direito Civil pelo CESUMAR. Especialista em Direito Empresarial pela UEL. Docente do Curso de Direito na Graduação e Pós-Graduação

\section{Mediação nos Casos de ViolênCIA CONTRA A Mulher}

\author{
Mediation in Cases of Violence \\ Against Women
}

Como citar: CANEZIN, Thays Cristina Carvalho. CANEZIN, Claudete Carvalho. CACHAPUZ, Rosane da Rosa. Mediação nos casos de violência contra a mulher. Revista do Direito Público, Londrina, v. 12 , n. 1 , p. 287-310, abr. 2017. DOI: $10.5433 / 1980-511 \times .2017 \mathrm{v} 12 \mathrm{n} 1 \mathrm{p} 287$. ISSN: 1980-511X.

Resumo: Ao longo dos anos as mulheres têm sofrido vários tipos de violência, sendo que, infelizmente, este cenário perdura até os dias atuais. Assim, analisa a questão do gênero, um conceito formulado pelas Ciências Humanas a fim de explicar como são construídas e de que forma se manifestam as diferenças culturais entre os sexos, e qual a relação com as desigualdades e discriminações que geram a violência contra a mulher, apresentando o instituto da mediação, como meio adequado de pacificação, tendo como objetivo o diálogo entre as partes, essencial nos casos de conflitos domésticos. 
Palavras-Chave: Gênero. Violência. Mulher. Mediação. Solução de conflito.

Abstrat: Throughout the years, women have suffered innumerable amounts of violence; unfortunately, these abuses still happen. With that said, this study analyzes the modern understanding of 'gender'-a concept formulated by social science academics in order to explain how cultural differences influences women and men. Moreover, this paper explores how cultural differences between both sexes are manifested, and investigates gender discrimination and inequality that generate violence towards women. In addition, this research presents mediation as an appropriate and adequate means for conflict resolution as it seeks party dialogue, which is essential in cases of domestic conflicts.

Keywords: Gender. Violence. Women. Mediation. Conflict resolution. em Direito Civil e Processual da UEL. Coordenadora do NEDDIJ e NUMAPE, Projetos de Extensão da UEL. Advogada. E-mail: claudetecanezin@uol. com.br. Telefone: (43) 99914641 .

*** Doutora em Direito Internacional, pela Pontifícia Universidade Católica de São Paulo. Mestre em Direito Negocial pela Universidade Estadual de Londrina. Graduada em Direito pela Universidade da Região da Campanha. Professora da Universidade Estadual de Londrina. Coordenadora dos cursos de Pós Graduação em Direito Empresarial, Direito de Família à Luz da Responsabilidade Civil, na Universidade Estadual de Londrina. Diretora cultural do Instituto Brasileiro de Direito de Família, IBDFAM-Londrina. E-mail: rozane_cachapuz@ hotmail.com 


\section{INTRODUÇÃO}

Não é de hoje que ouvimos falar sobre casos de violência contra a mulher, este abuso se arrasta por longo período de tempo, em várias etnias e posições sociais. A cultura das desigualdades sociais, econômicas e políticas estruturais entre homens e mulheres, a diferenciação rígida de papéis impostos pela cultura machista, as noções de virilidade ligadas ao domínio e à honra masculina estão enraizados, infelizmente, por toda sociedade.

Seu impacto não se observa apenas no âmbito individual, mas implica perdas para a segurança, bem como para o bem-estar de toda a comunidade, revelando-se verdadeira afronta aos direitos humanos.

A prática da violência contra o gênero feminino ao longo da história não é fruto da natureza humana, mas do processo de socialização das pessoas. A cultura patriarcal é uma característica histórica da nossa sociedade que perdura até os dias atuais, ainda é possível observar muitos traços dessa cultura, o que contribui para a criação de muitas situações conflituosas que podem levar, inclusive, às agressões físicas, verbais, morais, psicológicas e até materiais.

Estudar a violência contra a mulher parece ser algo recorrente, haja vista que muitas são as notícias de casos onde as mulheres são vítimas das mais variadas formas de agressão. $\mathrm{O}$ fenômeno da hostilidade somente parece incomodar quando atinge o físico, pois as marcas são visíveis, todavia, existem outras maneiras de violentar direitos inerentes à mulher. Tais violações não dizem respeito somente aos direitos específicos à condição feminina, mas aos direitos humanos em geral.

Neste cenário de dor, angústia e desespero, a tutela jurisdicional é vorazmente almejada como a única proteção capaz de cessar as 
agressões. Por muito tempo acreditou-se que somente o Estado era detentor jurisdicional, capaz de solucionar os conflitos interpessoais. Ocorre que com o advento da era moderna, muitos paradigmas foram modificados.

O movimento de acesso à justiça busca atender aos anseios da população oferecendo instrumentos processuais efetivos no intuito de reduzir a litigiosidade incorporando método de pacificação social.

Acompanhando as transformações das sociedades contemporâneas, e o aumento da consciência em relação aos direitos individuais e coletivos, a sociedade enfrenta hoje o que se convencionou chamar de a "desjudicialização" da resolução dos conflitos, ou seja, os litígios não precisam, necessariamente, ser solucionados pelo Poder Judiciário, ao contrário, passou-se a valorizar os meios adequados para resolução dos litígios e, dentre eles, destaca-se a mediação.

O Código de Processo Civil de 2015 enuncia, de maneira inédita, dentre as suas normas fundamentais, a promoção da solução consensual dos conflitos pelo Estado, a ser estimulada por todos os operadores do Direito, em seu art. $3^{\circ}, \S \S 2^{\circ}$ e $3^{\circ}$. Neste sentido, a legislação reforça a devida importância da mediação, ao lado do processo judicial, como instrumentos de pacificação social e de realização do direito de acesso à Justiça.

Ao se defender a cultura de paz, não se pode deixar de destacar a violência contra a mulher, assunto bastante polêmico que lamentavelmente ocorre em todo o mundo, e perpassa as classes sociais, as diferentes etnias e independe do grau de escolaridade.

Assim, ancorada no método dedutivo, a pesquisa se divide em três capítulos delimitados, buscando-se a consecução do objeto proposto a partir da análise individualizada do conflito de gênero, a conceituação 
do meio alternativo de solução de conflito, e por fim, a aplicação da mediação nos casos de violência que, por meio do diálogo, possa garantir o exercício da autonomia e da igualdade na vida das mulheres vítimas de violência doméstica.

\section{CONFLITOS DE GÊNERO}

A espécie humana é essencialmente dependente da socialização, sendo comum a ideia de que existe um tipo esperado de comportamento para cada um dos sexos a qual se espera que os homens sejam viris, machos, determinados e fortes, ao passo que das mulheres maternais, delicadas, femininas e dóceis.

Neste cenário cultural e social, o gênero desponta como uma linguagem, uma forma de comunicação, uma ordenação do mundo que orienta a conduta das pessoas e que, muitas vezes, é base para preconceitos, discriminação e exclusão social.

Isto significa dizer que os gêneros são produtos da realidade social, motivo pelos quais homens e mulheres são tão diferentes entre si, dependendo do meio social e cultural onde vivem. A base conceitual do gênero, que há machos e fêmeas na espécie humana é definida pela ciência, mas de ser homem ou de ser mulher é socialmente constituída, ou seja, pela cultura. (HEILBORN, 2001, p. 38).

Neste sentido, gênero é um conceito formulado pelas Ciências Humanas a fim de explicar como são construídas e de que forma se manifestam as diferenças culturais entre os sexos, e qual a relação dessas diferenças com as desigualdades e discriminações. (MUSZKAT et al., 2008, p. 28). 
A violência de gênero contra as mulheres não é assunto recente. De modo infeliz, a prática é antiga e encontra-se historicamente ligada ao lugar social que o Estado e a sociedade determinavam para elas. Outrora, eram submissas aos pais ou aos maridos, sempre consideradas propriedades de algum homem, não tinham capacidade civil ou qualquer poder sobre a família, nos moldes do antigo pátrio poder.

Após as grandes revoluções, as mulheres ganharam espaço no cenário social, porém continuam lutando pelas conquistas de seus direitos e contra uma cultura de dominação masculina.

Atualmente, a despeito de poucos exemplos, elas começaram a ocupar lugar de destaque na sociedade, nunca antes conquistados. Apesar dos êxitos, continuam sendo vítimas de violência doméstica, de preconceitos e de muitos estereótipos. Por mais que se lute, o considerado "sexo frágil" ainda sofre o peso de um passado sexista. (CANEZIN; PANICI, 2016, p. 3).

Especificamente no caso brasileiro, enraizada na história e no costume, a violência doméstica contra a mulher decorre da herança cultural, fruto de uma sociedade escravocrata face ao modelo colonizador que pregou a hierarquia e o preconceito.

Em tal sentir, o problema da subordinação e da discriminação da mulher não está na mulher:

Mas está nas pretensas formas de organização e de convívio, isto é, de exploração e dominação criadas, mantidas e atualizadas pela sociedade, que através do tempo, legitimam a superioridade e a consequente dominação dos homens sobre as mulheres, dos brancos sobre os negros e índios e da classe dominante sobre a classe operária. A subordinação da mulher ao homem mostra que as 
relações entre homens se produzem e se reproduzem dentro do processo social como um todo, e a maneira como estas relações se produzem e reproduzem, em detrimento das mulheres (NASCIMENTO, 2010, p. $1)$.

Da análise da diferença no tratamento entres homens e mulheres, possível compreender o significado da expressão violência de gênero, que não são as diferenças biológicas entre homens e mulheres que determinam o emprego da violência contra a mulher, mas os papéis sociais impostos a elas, reforçados por culturas patriarcais que estabelecem relações de violência entre os sexos. "O conceito de gênero, é usado para explicar as diferenças construídas entre homens e mulheres, refutando a justificativa de que essas diferenças são sempre biológicas e, portanto, naturais". (CAMPAGNOLI, 2003, p. 147).

De fato, o fenômeno da violência, na modalidade de gênero, pode ser explicado como uma questão cultural que se situa no incentivo da sociedade para que os homens exerçam sua força de dominação e potência contra as mulheres, sendo essas dotadas de uma virilidade sensível. Assim, as violências física, sexual e moral não ocorrem isoladamente, visto que estão sempre relacionadas à violência emocional.

Neste contexto, a violência contra a mulher pode ser entendida como o produto de uma construção histórica, trazendo uma estreita relação com as categorias de gênero, classe e etnia e suas relações de poder.

Infelizmente, na maioria das vezes a violência contra a mulher ocorre no ambiente doméstico, intrafamiliar. O agressor é sempre alguém de confiança e do convívio da vítima, o que leva a repensar uma forma de reorganização do núcleo pessoal. 
A família, seio da sociedade, que deveria envolver seus membros na segurança, no afeto, no respeito mútuo e na cooperação, torna-se espaço para a violência, abuso, agressão e maus tratos, por muitas vezes, de forma silenciada.

\subsection{Conflitos na Família - A Violência Contra a Mulher}

A família como organização social representa o primeiro núcleo de constituição e de socialização dos indivíduos. É de conhecimento geral que para uma sociedade ou um grupo funcione, é preciso haver uma divisão de tarefas, assim, parece natural que, num primeiro momento, esta partilha se estabeleça de acordo com o gênero.

Ao longo da história, o papel da mulher era da procriação e do cuidado da casa e de seus entes, em contrapartida, cabia aos homens garantir que nada faltassem para o sustento de sua família.

Hodiernamente, ante tantas transformações culturais e sociais, apesar de muitas mulheres não serem somente "donas-de-casa", e de muitos homens participarem do cenário doméstico, esperam-se, ainda, que os homens sejam, sobretudo, um bom provedor e as mulheres ainda são vistas como coadjuvante.

Muitas das entidades familiares estão enraizadas no modelo arcaico, tendo suas funções distintas e definidas, cabendo aos homens a aquisição e distribuição de bens, e às mulheres a criação e educação da prole. No entanto, a divisão das tarefas não é baseada na natureza biológica, como frequentemente se acredita, mas na herança ultrapassada do núcleo familiar.

As relações familiares baseiam-se, assim, nos princípios de 
hierarquia, subordinação, poder e obediência. Ou seja, o foco está mais no cumprimento das normas impostas pela sociedade do que, de fato, pela qualidade das inter-relações. (MUSZKAT et al., 2008).

Apesar dos modelos familiares sofrerem modificações a passos lentos, sua organização não se baseia única e exclusivamente na distribuição de poder, mas também dos afetos.

Essa divisão e a forma como é valorizada e reconhecida em nossa sociedade geram uma série de conflitos. O funcionamento e as organizações das famílias se baseiam na distribuição dos poderes, mas também dos afetos, e tendem a criar uma dinâmica complexa de competições e disputas no espaço doméstico. É equivocado pensar que essas disputam sejam orientadas exclusivamente pelas lutas de poder entre os sexos, porque são também motivadas pela conquista de espaços que garantam o amor, o reconhecimento e a proteção, necessidades básicas da condição humana. Ou seja, ao contrário da visão comumente romantizada de família, o espaço familiar é densamente carregado de conflitos. O nível de intimidade e de disputa dos afetos estimulam sentimentos ambíguos de amor e ódio, aliança e competição, proteção e domínio entre todos os membros de uma família (MUSZKAT et al., 2008, p. 35).

Deve ser destacado que, embora o modelo nuclear de família ainda seja valorizado pelas sociedades ocidentais, as obrigações e funções não obedecem mais aos padrões da família hierarquizada. As mudanças nos papéis sociais dos homens e das mulheres produziram a necessidade 
de ressignificar a família e seus conflitos, levando em conta seus aspectos mais complexos.

Se faz necessário, assim, reequilibrar poderes, derivando daí a noção de que a mulher não pode mais figurar como o polo mais frágil em uma relação. Igualmente, é preciso que se reavaliem os modelos de masculinidade e feminilidade que orientam as relações sociais em nossa cultura, com o intuito de superar as diferenças de poder e desigualdades entre os sexos.

As relações de gênero tendem a ser concebidas e praticadas de maneira mais ríspida quando se rompe com as atribuições que se esperam socialmente de um homem ou de uma mulher. É como se houvessem entre os parceiros um contrato implícito, apoiado nas expectativas de gênero. Contudo, como as transformações culturais e sociais exigem novos comportamentos e outras soluções, instauram-se o conflito, abrindo espaço para a manifestação da violência.

É neste contexto cultural e social que desponta a violência contra a mulher. Há diversos tipos de violência, em modalidades físicas, verbais, morais, psicológicas, patrimoniais, simbólicas. Ocorre em ações de discriminação, desqualificação, agressão, ameaça ou coerção. (ZAPPAROLLI, 2013).

As violências de gênero são ocasionadas em face da condição feminina ou masculina do ser humano. Violência contra a liberdade sexual, face a sexualidade da pessoa. Em ambas as hipóteses, independentemente de aspectos de raça, classe social, religião, idade, ou qualquer outra condição. Já, as violências domésticas, são aquelas ocorridas num ambiente doméstico ou em uma relação de familiaridade, afetividade ou coabitação, onde haja vínculos de parentesco, civil ou de afeto. (ZAPPAROLLI, 2013). 
Muitas vezes, nas ambiências dos crimes de gênero ou familiar as partes continuam vivendo e convivendo sob o mesmo teto, apesar da propositura de uma ação judicial. Isso produz revolta o que acirra as violências em suas distintas tipificações agravando situações já bastante difíceis.

O sistema jurídico e as práticas judiciárias tradicionais não dão conta da problemática. Em grande escala, deparam-se com relações que se perpetuam e reproduzem-se de forma violenta, tanto em complementaridade, como em simetria, exibindo elevado grau de morbidez e impermeabilidade, num equilíbrio homeostático que estabiliza essas relações em patamares violentos não questionados ou, se questionados, de difícil rompimento. Há, ainda, aspectos culturais que dificultam o rompimento dos vínculos conjugais e familiares não funcionais $\mathrm{e}$ estruturados em bases violentas (ZAPPAROLLI, 2013, p. 189).

Pesquisas já comprovaram que os conflitos e as violências domésticas têm reflexos sociais relevantes, inclusive na economia. Dados do Banco Mundial divulgados recentemente indicam que 1 em cada 5 dias de falta feminina ao trabalho decorrem de violências domésticas. Igualmente, filhos de famílias violentas tendem a reproduzir essa violência, ocasionando reflexos gravosos à sociedade.

Em relacionamentos que prevalecem a violência é possível perceber que o Estado é demandado pelas mesmas partes, em razão dos mesmos conflitos, por diversas vias. Este panorama tende a dificultar um olhar global sobre o conflito, levando ao excesso de demandas judiciais 
com seus infindáveis recursos que geram o sentimento de ausência ou ineficácia da ação do Estado e do Poder Judiciário. (ZAPPAROLLI, 2013).

Como meio de auxiliar os casos menos complexos de violência contra a mulher, a Mediação parece ser um instrumento eficaz na condução desses conflitos continuados, pelas razões que passam agora a ser analisados.

\section{DO INSTITUTO DA MEDIAÇÃO}

Não se olvida que atualmente os números de conflitos existentes ultrapassam o aparato judicial, todos os cidadãos procuram o Judiciário para a resolução das mais diversas contendas, entretanto, alguns empecilhos são suportados, como a falta de estrutura, o tempo de duração do processo, os vários recursos existentes nas legislações, para ao final obterem decisões para seus casos.

No vocabulário jurídico, conflito é sinônimo de entrechoques de ideias ou de interesses, em decorrência do qual se instala uma divergência entre fatos, pessoas ou coisas. (SILVA, 2014, p. 187).

Diante dos entraves do Poder Judiciário, há mecanismos de solução de conflito capaz de oferecer decisões em tempo exíguo e com grau de especialidade sobre cada caso. Neste contexto, merece destaque a mediação, posto que consiste em um recurso que tem o condão de assegurar o acesso à justiça, revelando-se um mecanismo somatório à atividade jurisdicional.

Dentro deste cenário o Novo Código de Processo Civil surge na esteira da Política Judiciária Nacional de tratamento adequado de conflitos 
de interesse no âmbito do Poder Judiciário, implementada pela Resolução 125, de 20 de novembro de 2011, do Conselho Nacional de Justiça. Informa ainda que os mecanismos de conciliação e mediação precisam ser integrados ao trabalho diário dos magistrados, como canais alternativos de exercício da função jurisdicional. E finaliza dizendo que os magistrados devem entender que conciliar é tarefa tão ou mais essencial e nobre que dirigir processos ou expedir sentenças (PELUZO, 2011, p. 15).

A Resolução 125 do Conselho Nacional de Justiça (CNJ) institui a mediação e a conciliação como políticas públicas de tratamento adequado de conflitos, in verbis:

[...] que a conciliação e a mediação são instrumentos efetivos de pacificação social, solução e prevenção de litígios, e que a sua apropriada disciplina em programas já implementados no país tem reduzido a excessiva judicialização dos conflitos de interesses, a quantidade de recursos e de execução de sentenças (BRASIL, 2010).

O marco revolucionário do acesso à justiça começou com obra de Mauro Capelletti e Bryan Garth (1988) ao desenvolver as três ondas renovatórias, defendendo um sistema mais acessível a todos e com resultados individual e socialmente justo. A primeira onda renovatória foi combatida pelos altos custos processuais, vez que propunha ao Estado o dever de garantir mecanismos que viabilizassem a proteção dos direitos a todos, sendo seus direitos postulados por advogados remunerados pelos 
cofres públicos.

A segunda onda renovatória, defendida pelos autores, indicou a criação de meios de defesa dos interesses supraindividuais, como a ação popular, a ação civil pública, código de defesa do consumidor, entre outras, ao permitir ao juiz proferir uma solução conjunta a várias pessoas em uma única ação. Em relação a terceira onda renovatória referem-se ao acesso a informação em juízo, possibilitando a utilização de várias instituições e mecanismos para resolver as controvérsias, como os meios adequados de resolução de conflitos, mediação, conciliação e arbitragem.

Assevera a doutrina que o método da mediação de conflitos surgiu no curso de Direito da Universidade Harvard, como alternativa extrajurídica para aliviar o judiciário, baratear os custos do processo, garantir o sigilo referente a litígios nas grandes empresas, entre outros. Trata-se, pois, a mediação de uma forma alternativa, pacífica, de resolução de conflitos, em que uma pessoa neutra, o mediador, ajuda as partes a superarem suas diferenças por meio do diálogo e da compreensão do objeto da controvérsia (MUSZKAT et al., 2008, p. 20). Consiste, pois, a mediação, em um dos instrumentos de pacificação de natureza autocompositiva e voluntária, no qual um terceiro, imparcial, atua de forma ativa ou passiva, como facilitador do processo de retomada do diálogo entre as partes, antes ou depois de instaurado o conflito (CAHALI, 2011).

Para Fernanda Tartuce (2015, p. 174), a mediação pode ser conceituada como:

Meio consensual de abordagem de controvérsias em que um terceiro imparcial atua para facilitar a comunicação entre os envolvidos para propiciar que eles possam, a partir da percepção ampliada dos meandros da situação 
controvertida, protagonizar saídas produtivas para os impasses que os envolvem.

Roberto Bacellar (2011, p. 32) discorre sobre o assunto conceituando a mediação da seguinte forma:

A mediação pode ser, grosso modo, definida como técnica que induz pessoas interessadas na resolução de um conflito a encontrar, por meio de uma conversa, soluções criativas, com ganhos mútuos e que preservem o relacionamento entre elas. Em outras palavras, ressalta tratar de diálogo assistido por um mediador, tendente a propiciar um acordo satisfatório para os interessados e por eles desejado, preservando-lhes o bom relacionamento.

Corroborando com o que foi dito, a mediação constitui um procedimento de transformação dos antagonismos em pontos de convergência, facilitando e estimulando o diálogo entre as partes. E assim, apoiada nos paradigmas das ciências modernas, a mediação, ao invés de se pautar em verdades absolutas, tem como característica básica aceitar a complexidade das relações interpessoais, assimilando as diferenças culturais e natureza dos conflitos.

Ao invés de imputar sentenças, a mediação procura dar voz às partes, estimulando-as a encontrar as próprias soluções, envolvendo cada parte no litígio a explicar seu posicionamento diante do conflito, defendendo suas necessidades, crenças e perspectivas.

Num segundo momento, convida a pessoa a adaptar suas necessidades às possibilidades reais de um acordo a ser cumprido, isto é, transfere a responsabilidade de decisão para as partes envolvidas no conflito, retirando de um terceiro, no caso o juiz, o poder de decisão.

A metodologia da mediação, portanto, é dar às pessoas 
envolvidas no conflito autonomia e autodeterminação, conferindo-lhes a liberdade de decidir. Assim, ao trabalhar com ambas as partes e verificar a responsabilidade de cada um pela situação geradora do conflito, permite que, feitos os devidos reparos, elas consigam dialogar e buscar formas pacíficas de obter o que consideram justo na solução da lide.

A Lei n. ${ }^{\circ} 13.140$ de 2015 (BRASIL, 2015) disciplina a mediação como meio adequado de solução de controvérsias e sobre a composição de conflitos no âmbito da Administração Pública. Igualmente, encontra-se elencada no artigo 165 do Código de Processo Civil de 2015, que trata dos instrumentos não jurisdicionais de solução de conflitos, com destaque para a autocomposição, a conciliação e a mediação, que deverão ser implementadas respectivamente pelas próprias partes, ou pelas partes e conciliadores, ou mediadores, em sessões ou audiências realizadas nos centros de cada Tribunal.

É possível extrair um conceito legal de mediação da combinação do artigo 165 , caput, com o parágrafo $3^{\circ}$ do Código de Processo Civil/2015, de modo que a mediação é o meio de solução consensual de conflitos, realizado por mediador, nos casos em que existir um vínculo anterior entre as partes, sendo um instrumento destinado a auxiliar os interessados a compreender as questões e os interesses em conflito, de modo que as próprias partes possam, pelo reestabelecimento da comunicação, identificar, por si, as próprias soluções consensuais que gerem benefícios mútuos.

Em contrapartida, o processo tradicional se inscreve em uma lógica de relação de forças, onde um ganha e outro perde, na mediação os interesses contraditórios são mediados, as posições antagônicas são fundidas e a solução é conjuntamente alcançada. $\mathrm{O}$ objetivo maior, portanto, é proporcionar a efetiva pacificação das partes litigantes, ou 
seja, a busca da composição amigável da disputa. (LOUREIRO, 1998).

É, pois, a mediação, importante técnica voltada à solução de conflitos para a pacificação social. Assim, auxiliados na tomada de decisões pelo mediador, os interessados estabelecem entre si a solução que melhor atenda suas necessidades e interesses, sem que haja total submissão ou renúncia de uma parte à outra.

É a introdução dessa nova mentalidade que prega a sobreposição da pacificação das partes à cultura da sentença que a mediação pretende alcançar. Neste cenário o mediador tem papel fundamental, posto que seu trabalho é conduzir as partes com habilidade, a fim de que elas mesmas encontrem a solução para seu conflito. O mediador nunca interfere; ele ensina as pessoas em conflito a pensar e expressar efetivamente o que estão sentindo. (LOUREIRO, 1998).

A mediação pode ser então definida como um método não adversarial, consensual e informal, pelo qual uma terceira pessoa imparcial, escolhida ou aceita pelas partes, auxilia os interessados a buscarem uma solução justa e adequada ao caso submetido à apreciação. Atuando de modo a facilitar a compreensão do problema, encoraja a resolução de uma divergência.

A mediação torna o processo mais equitativo e legítimo, uma vez que um processo mediado pode exprimir melhor a realidade dos fatos, estimulando a corresponsabilidade das partes na resolução do conflito.

Esse mecanismo de solução de conflitos visa, então, fornecer ao mediando a possibilidade de rever os seus padrões de conduta, servindo a mediação para administrar as diferenças que existem entre os seres humanos, a fim de instalar o diálogo onde ele não existe.

De fato, a solução pacífica das controvérsias é um objetivo ínsito ao ordenamento jurídico nacional. Inegável, pois, que seja 
particularmente almejado nas relações familiares visto que, sendo a família a célula-mãe da sociedade, seu enfraquecimento, pelo motivo da controvérsia, compromete a integridade do corpo inteiro, provocando consequências gravíssimas na sociedade.

Sensível a essa realidade, o legislador constituinte entendeu ser a família a base da sociedade e, nessa condição, merecedora de especial proteção por parte do Estado. Assim, quando o Código de Processo Civil prevê que nas ações de família o norte a ser perseguido será o da consensualidade está, antes de tudo, permitindo que as ações envolvendo relações familiares conflituosas possam ser analisadas através da mediação.

\section{MEDIAÇÃO NOS CASOS DE VIOLÊNCIA CONTRA A MULHER}

A mediação, como instrumento de pacificação social, pode ser aplicada em casos de menor potencial ofensivo a mulher, não propõe o afastamento do Judiciário, mas meio de auxiliar as soluções das controvérsias quando passíveis de composição amigavelmente. Malvina Ester Muszkat, Maria Coleta F. A. de Oliveira, Sandra Unbehaum e Susana Muszkat defendem que no campo penal, mesmo sofrendo maior resistência, acabou ganhando espaço no atendimento de jovens com condutas delituosas, visto que o método possibilita eficiência preventiva e atenção à vítima (MUSZKAT, et al., 2008, p. 21).

Somadas a todas as características da mediação já mencionadas anteriormente, vale destacar, também, que a mediação age com o sujeito inter-relacionado no mundo, com seus oponentes, sua família, sua 
comunidade e a sociedade à qual pertence. Igualmente, leva em conta as dificuldades e os problemas intrapsíquicos e sociais que dificultam o redimensionamento das partes conflitantes.

O objetivo da mediação não é necessariamente a obtenção de um acordo, mas gerar a transformação no padrão de comunicação entre os mediandos, para a construção da funcionalidade relacional. A mediação pode levar ao acordo, proporcionando opções e soluções mutuamente satisfatórias construídas pelos próprios mediandos. Isso não faz com que seja o acordo o objetivo da mediação. Nessa hipótese não se deve perder de vista a totalidade do conflito que não se resume apenas as disputas pontuais (ZAPPAROLLI, 2013, p. 191).

Fazer um acordo não significa, necessariamente, que haverá a transformação do padrão de relacionamento, no caso em tela, a violência contra a mulher. Ora, em muitas situações, mesmo havendo um acordo, e se extinguindo o processo, o conflito que o originou permanece. Assim, resolve-se o processo específico, mas não se soluciona o conflito, ou seja, os motivos que levaram àquele processo judicial.

Daí a importância da mediação, que não busca apenas a obtenção de acordos setorizados, mas visa também proporcionar instrumentos aptos a produzir transformações na forma dos mediandos se comunicarem e se relacionarem.

Como já mencionado, o mediador busca melhorar o diálogo entre as partes. Para isso, usa técnicas específicas como a escuta ativa para identificar a posição das partes, interesses e sentimentos 
do casal envolvido num conflito. Neste sentido, o mediador ajuda as partes a compreenderem melhor a situação em que estão envolvidos, proporcionando a conscientização, a autonomia e a flexibilização de suas condutas.

Destaca-se, a importância do mediador neste processo, sendo terceiro, escolhido ou aceito pelas partes, que rege o processo com equidistância, questiona as partes respeitosamente, busca os reais interesses de cada um dos mediandos. Igualmente, trabalha em regime de confidencialidade, não é juiz, não decide e não aconselha.

O mediador facilita a comunicação, possibilita a escuta recíproca e a reconstrução das narrativas, e resgata as habilidades dos sujeitos para que se sintam capazes de decidir e de gerir seus próprios conflitos. Portanto, a mediação não se destina à intervenção em situações de crise, nos momentos em que estão ocorrendo as violências ou crimes.

Nos casos das relações continuadas, como são as relações de violência contra a mulher, visto que geralmente ocorrem no seio familiar, a apropriação dos conflitos nas políticas públicas, de maneira sistêmica, vai além das atribuições do Judiciário como imperativo de sua efetividade, pois este visa também evitar a reincidência e o agravamento desses conflitos. (ZAPPAROLLI, 2013).

Decorre daí a importância da mediação nos casos que envolvem a violência doméstica contra a mulher, posto que visa entreabrir e facilitar o diálogo entre as partes, fazendo frente aos conflitos sociais e às violências estruturais que permeiam a relação.

\section{CONCLUSÃO}

A solução pacífica dos conflitos é um objetivo intrínseco 
ao ordenamento jurídico nacional. Inegável, igualmente, que essa pacificidade seja almejada nas relações familiares, relações de afeto, uma vez que, sendo a família a célula mãe da sociedade, seu adoecimento produz gravíssimos reflexos na sociedade como um todo.

Merecedora, pois, de especial proteção do Estado, a família, e todas as relações que a permeiam, deverão ter seus conflitos perseguidos pela consensualidade, sempre que possível. O diálogo e a mudança de comportamento devem ser os objetivos maiores.

Neste sentido, a mediação de conflitos encontra-se no centro da discussão a respeito do papel do direito nos conflitos de Família em nossa sociedade, e da possibilidade de dotá-lo de maior capacidade de gerar repercussões positivas na vida das pessoas.

O incentivo de se adotar a mediação nos casos de violência contra a mulher decorre de uma tentativa de mudança de paradigmas, em que o objetivo maior é transformar em uma relação satisfatória e pacífica.

É, pois, a mediação um mecanismo complexo de intervenção sobre relações interpessoais em conflito, conduzida por profissionais treinados a partir de um conjunto de técnicas, estratégias e principalmente, de saberes, que buscarão facilitar o diálogo através da descoberta, pelas partes, de afinidades que lhes permitam afastar as diferenças e transformar os conflitos.

É preciso se ter em mente que entre um casal, no seio de sua família ou em qualquer outro ambiente, os conflitos nunca desaparecem, eles apenas se transformam. Isso acontece em consequência de diferenças culturais, sociais ou ideológicas. Por esta razão, e em especial nos conflitos pessoais, é recomendável intervir sobre si mesmo, repensar os conceitos e atitudes, a fim de melhorar as relações.

A mediação, portanto, como um instrumento de facilitação de 
diálogos, é meio adequado e efetivo a fim de reestabelecer a comunicação entre as pessoas onde esteja insuficiente ou obstaculizada, configurandose elemento adequado e efetivo na resolução de conflitos e agressão à mulher, uma vez que visa não apenas solucionar o conflito, mas transformar a situação, a fim de concretizar princípios constitucionais tradutores, especialmente, os da dignidade da pessoa humana.

\section{REFERÊNCIAS}

BACELLAR, Roberto Portugal. O poder judiciário e o paradigma da guerra na solução de conflitos. In: PELUSO, Antonio Cesar; RICHA, Morgana de Almeida. (Coord.). Conciliação e mediação: estruturação da política judiciária nacional. Rio de Janeiro: Forense, 2011.

BRASIL. Conselho Nacional de Justiça. Resolução no 125, de 29 de novembro de 2010. Dispõe sobre a Política Judiciária Nacional de tratamento adequado dos conflitos de interesses no âmbito do Poder Judiciário e dá outras providências. Disponível em: $<$ http://www.cnj. jus.br/busca-atos-adm?documento=2579>. Acesso em: 5 mar. 2017.

BRASIL. Lei $\mathbf{n}^{\mathbf{0}} \mathbf{1 3 . 1 4 0}$, de 26 de junho de 2015. Dispõe sobre a mediação entre particulares como meio de solução de controvérsias e sobre a autocomposição de conflitos no âmbito da administração pública; altera a Lei no 9.469, de 10 de julho de 1997, e o Decreto no 70.235 , de 6 de março de 1972; e revoga o § 2o do art. 6o da Lei no 9.469, de 10 de julho de 1997. Disponível em: $<$ http://www.planalto. gov.br/ccivil_03/_ato2015-2018/2015/Lei/L13140.htm>. Acesso em: 5 mar. 2017.

CAHALI, Francisco José. Curso de arbitragem, mediação, conciliação, Resolução CNJ 125/2010. São Paulo: Revista dos Tribunais, 2011. 
CAMPAGNOLI, Adriana de Fátima Pilatti. A mulher, seu espaço e sua missão na sociedade. Análise crítica das diferenças entre os sexos. Revista Emancipação, Recife, ano 3, v. 3, n. 1, p. 174, 2003.

CANEZIN, Claudete Carvalho; PANICHI, Edna Regina Pugas. Lei Maria da Penha: um meio para coibir o discurso da violência contra mulher. Londrina, 2016. (no prelo).

CAPPELLETTI, Mauro; GARTH, Bryant. Acesso à justiça. Porto Alegre: Ed. Fabris, 1988.

HEILBORN, M. L. Sexualidade e identidade: entre o social e o pessoal. In: CIÊNCIA hoje na escola. São Paulo: Global, 2001. p. 3841 (Sexualidade, corpo, desejo e cultura, v. 11).

LOUREIRO, Luiz Guilherme de Andrade Vieira. A mediação como forma alternativa de solução de conflitos. Revista dos tribunais, São Paulo, v. 751, p. 94-105, maio 1998.

MUSZKAT, Malvina E. et al. Mediação familiar transdisciplinar: uma metodologia de trabalho em situações de conflito de gênero. São Paulo: Summus, 2008.

NASCIMENTO, Maria Lucidalva. Violência doméstica e sexual contra as mulheres. 2010. Disponível em: $<\mathrm{http}: / /$ araretamaumamulher.blogs.sapo.pt/13812.html>. Acesso em: 10 maio 2016.

PELUZO, Cesar. Mediação e conciliação. Revista de Arbitragem e Mediação, São Paulo: Revista dos Tribunais, 2011. v. 30.

SILVA, De Plácido. Conflito. In: . Vocabulário jurídico. 31. ed. Rio de Janeiro: Forense, 2014. p. 187.

TARTUCE, Fernanda. Mediação nos conflitos civis. 2. ed. Rio de Janeiro: Forense; São Paulo: Método, 2015. 
ZAPPAROLLI, Célia Regina. A experiência pacificadora da mediação. In: MUSZKAT, Malvina. Mediação de conflitos: pacificando e prevenindo a violência. São Paulo: Summus Editorial, 2013. p. 149189.

Como citar: CANEZIN, Thays Cristina Carvalho. CANEZIN, Claudete Carvalho. CACHAPUZ, Rosane da Rosa. Mediação nos casos de violência contra a mulher. Revista do Direito Público, Londrina, v. 12, n. 1, p. 287-310, abr. 2017. DOI: 10.5433/1980-511x.2017v12n1p287. ISSN: 1980-511X.

Recebido: 23/03/2017

Aprovado: 25/03/2017 